\title{
DOSSIÊ TEMÁTICO: DEMOCRACIA E DESENVOLVIMENTO
}

\section{THEMATIC DOSSIER: DEMOCRACY AND DEVELOPMENT}

\author{
Sandro Luiz Bazzanella ${ }^{1}$, Gladis Camarini ${ }^{2}$ \\ ${ }^{1}$ Titulação máxima, nome da instituição em que autor 1 está filiado, cidade, UF, país, e-mail \\ ${ }_{2}^{2}$ Professora Titular, Centro Universitário do Sul de Minas - UNIS - MG, Mestrado em Gestão e Desenvolvimento Regional, Varginha, \\ MG, Brasil, gcamarini@gmail.com
}

\section{Resumo}

Este Editorial apresenta o dossiê temático “Democracia e Desenvolvimento" em parceria com o Programa de PósGraduação em Desenvolvimento Regional da Universidade do Contestado - UnC. Os trabalhos envolvem como tema central o desenvolvimento regional a partir de temáticas: políticas públicas e desenvolvimento; direito e desenvolvimento, economia e desenvolvimento; estado de exceção e desenvolvimento; meio ambiente e desenvolvimento; movimentos sociais e desenvolvimento; educação e desenvolvimento, compondo o dossiê. Esperamos que os textos do dossiê contribuam para a divulgação científica proporcionando a formação intelectual e a reflexão crítica dos leitores.

Palavras-chave: Democracia. Desenvolvimento. Desenvolvimento Regional.

\begin{abstract}
This Editorial presents the thematic dossier "Democracy and Development" in partnership with the Graduate Program in Regional Development at the University of Contestado - UnC. The works central theme is regional development based on other subjects: public policies and development; law and development, economics and development; state of exception and development; environment and development; social movements and development; education and development, which compose the dossier. We hope that these texts contribute to scientific dissemination by providing intellectual training and critical reflection for readers.
\end{abstract}

Keywords: Democracy. Development. Regional Development. 


\section{EDITORIAL}

Na contemporaneidade, compreender a abrangência e as exigências da democracia em sua relação com o desenvolvimento regional requer que se compreenda a dinâmica institucional constitutiva do Estado como poder constituído legitimado representativamente pelo poder constituinte. Trata-se, sobretudo, questionar o papel do Estado como pode soberano dinamizador de um projeto de desenvolvimento nacional que se ramifica e se materializa na formulação e gestão de políticas públicas de fomento do desenvolvimento local e regional.

Diante das instabilidades políticas, jurídicas, sociais e econômicas em que a sociedade e o Estado brasileiro se encontram torna-se urgente refletir sobre a relação entre democracia e desenvolvimento. Constatam-se cotidianamente discursos dos mais diferentes matizes em defesa da democracia demonstrando que a democracia se tornou um imperativo que define as formas de vida de indivíduos, de comunidades, regiões, povos e países. Esta importância vital que a democracia representativa assume na atualidade é decorrente dos movimentos sociais, políticos, culturais e econômicos constitutivos da ocidentalidade e, na forma do estado de direito intensificou-se na modernidade aos dias atuais.

Sob tais perspectivas, mede-se a qualidade de vida de regiões, povos e países pelo seu dinamismo democrático. Associa-se diretamente desenvolvimento local, regional a partir da dinâmica de suas instituições, bem como da participação dos cidadãos em conselhos, em deliberações de questões públicas e de interesse do bem comum. Ou seja, vincula-se de forma tácita que considerar uma região desenvolvida implica necessariamente em reconhecer seu respeito às instituições, bem como seu envolvimento com as questões de interesse público.

É sob tais pressupostos, que a Revista Interação publica este dossiê que tem como tema central o desenvolvimento regional que se articulam a partir de temáticas como: políticas públicas e desenvolvimento; direito e desenvolvimento, economia e desenvolvimento; estado de exceção e desenvolvimento; meio ambiente e desenvolvimento; movimentos sociais e desenvolvimento; educação e desenvolvimento, compondo o dossiê: "Democracia e Desenvolvimento".

Este dossiê se justifica como compromisso teórico e prático em compreender os movimentos que levaram a democracia representativa assumir a condição na qual nos encontramos inseridos e, quais os impactos desta condição no desenvolvimento de comunidades, de regiões, povos e países. Toda a comunidade acadêmica brasileira é convidada a colaborar com estudos teóricos e empíricos sobre a questão regional no Brasil.

Sob esta perspectiva, a Revista Interação publica o presente dossiê com 07 artigos, em parceria com os pesquisadores do Programa de Pós-Graduação em Desenvolvimento Regional PPGDR, da Universidade do Contestado, que se articulam em torno do desenvolvimento regional.

$\mathrm{O}$ artigo Impactos da Lei $\mathbf{1 4 . 0 1 0 / 2 0}$ sobre a execução de alimentos pelo enfoque da teoria dos jogos, que avalia, a partir da pandemia do coronavírus (Covid-19) no Brasil, a implantação da Lei no 14.010, de 10 DE junho de 2020 que dispõe sobre o Regime Jurídico Emergencial e Transitório das relações jurídicas de Direito Privado (RJET) no período da pandemia. O objetivo foi compreender os impactos da Lei 14.010/20 sobre a execução de alimentos pelo enfoque da Análise Econômica do Direito (AED), mais especificamente pela Teoria dos Jogos.

Após esse debate, apresenta-se o artigo Implicações socioambientais do desenvolvimento econômico, com base em metodologia bibliográfica e documental são investigadas as relações que permeiam a vida humana e as práticas ambientais, as quais, desde a era moderna, estão constante e diretamente associadas aos discursos e práticas jurídicas e econômicas. 
Continuando as discussões sobre o desenvolvimento regional, apresenta-se um artigo com a Análise dos impactos da concessão do setor ferroviário de cargas na década de 1990. Destaca que o processo de concessão das malhas ferroviárias foi uma forma de eliminar as dívidas do setor ferroviário brasileiro. Verificou-se um aumento de investimentos tanto do setor privado quanto do setor público, redução no número de acidentes, aumento de empregos diretos e indiretos e maior participação na produção de transporte de cargas. O minério de ferro é a carga que tem o maior volume de transporte pelo modal ferroviário, chegando a quase $80 \%$ de toda carga que foi transportada no ano de 2018. Conclui que após a concessão houve mais impactos positivos do que negativos.

A inovação e a sustentabilidade, temas relevantes para o desenvolvimento, foram abordadas no artigo Fundamentos para pensar a inovação sustentável, o qual faz uma reflexão para despertar o debate sobre a origem e o significado da autêntica forma de pensar a inovação compatível com preservação do meio ambiente, por meio de num sistema econômico ocupado e comprometido com o equilíbrio do planeta, no presente e no futuro.

A Institucionalização de crianças e adolescestes e a adoção tardia em União da Vitória-PR foi abordada por meio de pesquisa bibliográfica e de campo nos serviços prestados pela rede de proteção social integral da criança e do adolescente institucionalizada em União da Vitória-PR, após a Lei no 8.069/1990, uma questão a ser enfatizada tanto no viés das atribuições institucionais, quanto dos profissionais que atuam na área.

Artigos sobre educação e desenvolvimento regional também foram abordados neste dossiê. Educação e desenvolvimento regional: a UNESCO e as interseções com o desenvolvimento regional contribui para a discussão da educação e desenvolvimento ao trazer as abordagens da UNESCO que defende o fortalecimento do Estado de Direito por meio da educação para formuladores de políticas da educação básica e superior.

O ensino médio profissionalizante e seus desdobramentos - produção brasileira recente evidencia os estudos realizados sobre as às percepções e/ou necessidades dos jovens do ensino médio sobre a vida, o estudo e o trabalho Ensino Médio profissionalizante.

Encerrando o dossiê, o artigo infância e educação infantil: representações sociais das famílias que aborda as representações sociais das famílias de crianças matriculadas na educação infantil na rede pública de educação municipal de São Paulo, sobre infância e educação infantil. Os resultados indicaram que a representação da infância se caracteriza como um período da vida de brincadeiras e descobertas, destacando a concepção social moderna para a temática.

Esperamos que os artigos do dossiê Democracia e Desenvolvimento contribuam para a divulgação científica proporcionando a reflexão crítica dos leitores.

Boa leitura!

Editores responsáveis:

- Prof. Dr. Sandro Luiz Bazzanella - Universidade do Contestado - UnC - Canoinhas/SC

- Profa. Dra. Gladis Camarini - Centro Universitário do Sul de Minas - UNIS-MG; 